
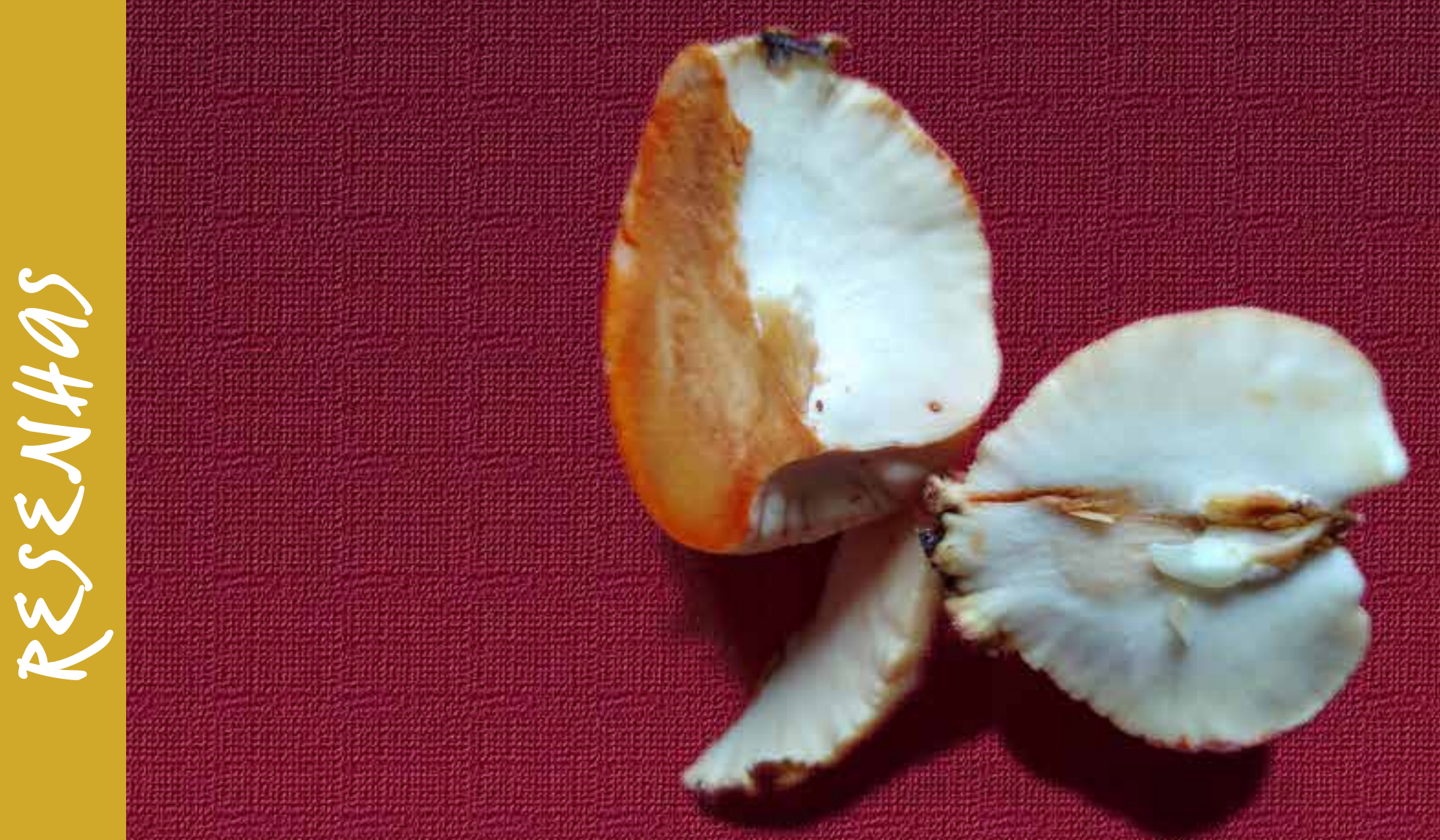

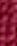

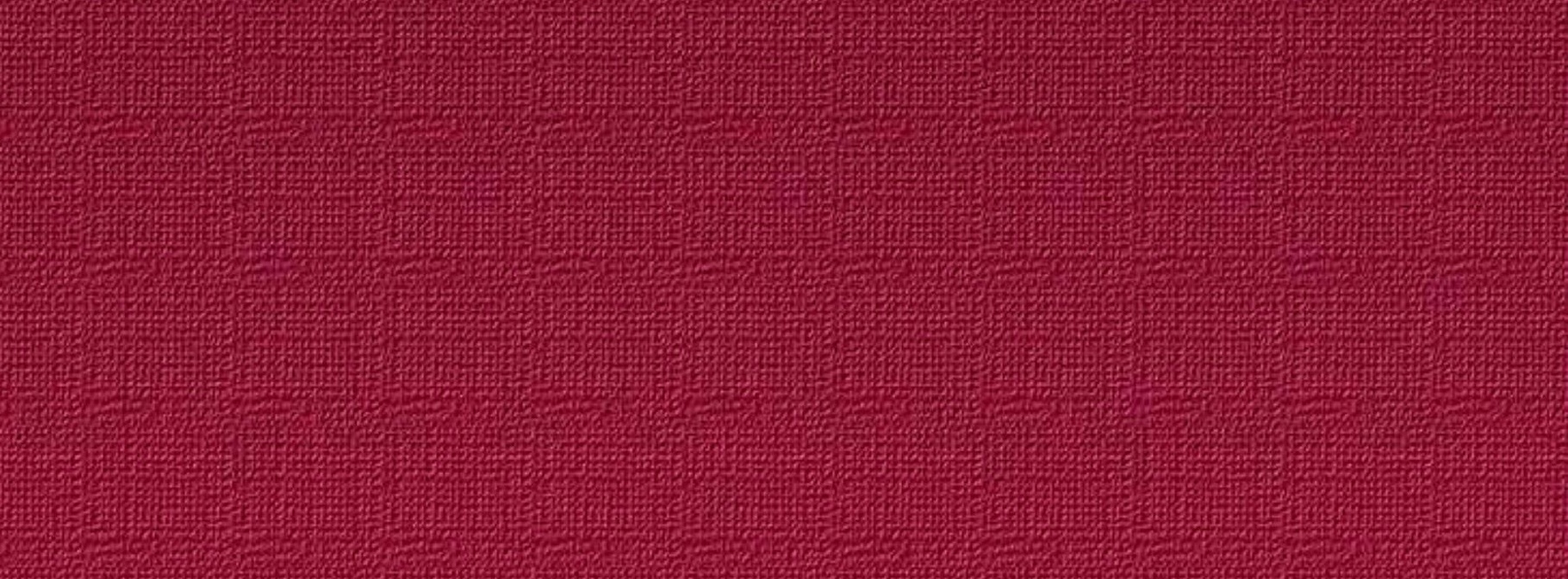




\title{
ESCOMBROS DA CIVILIZAÇÃO: A CRISE DOS REFUGIADOS EM JULIETA MONGINHO
}

\author{
RUBBLE OF CIVILIZATION: THE REFUGEE \\ CRISIS IN JULETA MONGINHO
}

Paulo Ricardo Kralik Angelini ${ }^{1}$

\section{RESENHA DE MONGINHO, JULIETA. UM MURO NO MEIO DO CAMINHO. PORTO: PORTO EDITORA, 2018.}

Assim Zygmunt Bauman inicia o seu livro Estranhos à nossa porta:

Os noticiários de TV, as manchetes de jornal, os discursos políticos e os tuítes da internet, usados para transmitir focos e escoadouros das ansiedades e dos temores do público, estão atualmente sobrecarregados de referências à "crise migratória" - que aparentemente estaria afundando a Europa e sinalizando o colapso e a dissolução do modo de vida que conhecemos, praticamos e cultivamos. $(2017$, p. 7$)$

Para o filósofo, a construção midiática em torno dos refugiados gera um pânico moral. De certo modo, a consolidação desse discurso suaviza ou mesmo endossa uma aceitação e um apoio a cenas de horror e de barbárie: "Crianças afogadas, muros apressadamente erguidos, cercas de arame farpado, campos de concentração superlotados" (BAUMAN, 2017, p.8). Trata-se os migrantes como "batatas quentes", transformando essas situações em uma rotina tediosa da normalidade.

É para o lado de fora do muro que vai se dirigir o olhar de Julieta Monginho. Não é de hoje que a literatura portuguesa traz personagens à 
margem para um espaço de protagonismo. Toda a literatura de José Saramago dá voz àqueles silenciados por séculos de opressão. Também há exemplos em Valter Hugo Mãe, Ricardo Adolfo, Alexandra Lucas Coelho, Ana Margarida de Carvalho, entre muitos outros nomes. Um muro no meio do caminho, de Julieta Monginho, não foge a essa regra; pelo contrário, exponencia a tradição ao colocar em cena o drama dos refugiados, elefante branco na sala de estar da Europa. O romance de Monginho foi destaque nas premiações de 2019 em Portugal, vencendo dois importantes concursos - Prêmio Literário Fernando Namora e Prêmio PEN Clube Português - e sendo finalista no Grande Prêmio de Romance e Novela da Associação Portuguesa de Escritores (APE).

Com um texto fluido, apoiado por silêncios e cedendo a voz a personagens migrantes, a narradora de Monginho confunde-se com a autora, ainda que o termo ficção esteja registrado nos dados catalográficos da obra e apareça num aparte do texto: "Este é um livro de ficção. Nenhuma das personagens, excepto J., corresponde a uma pessoa real" (MONGINHO, 2018, p. 245). A personagem J. tem inclusive um capítulo na obra. Julieta - a J.? -, a autora, é magistrada do Ministério Público, tem histórico de longa luta social e foi voluntária na Grécia, no campo de Vial, na ilha de Chios, em 2016. E essa experiência, o convívio diário com as gentes que sobreviveram (e sobrevivem) a árduas travessias em busca de uma vida melhor, rendeu-lhe as personagens de Um muro no meio do caminho, referência óbvia, aliás, ao conhecido poema de Drummond. Destaco os únicos versos que escapam da redundância sonora do poema: "Nunca me esquecerei desse acontecimento/ Na vida de minhas retinas tão fatigadas." (DRUMMOND, 2008, p. 267)

Pois esses acontecimentos ecoaram em Monginho e, no mundo ficcional, surgem como gênese do processo de escrita. J., depois de meses de dedicação à causa, retorna a Lisboa. Enquanto pensa no merecido descanso, continua a receber dezenas de pedidos de socorro por e-mail, mas precisa dar um fim àquilo. Precisa escrever: "A interrupção abrupta deu origem a estas notas, às personagens deste livro. A ligação aos que vi agonizar às portas da Europa é impossível de interromper" (MONGINHO, 2018, p. 122).

Os três primeiros capítulos de Monginho são engenhosos e bastante promissores. O leitor é apresentado a Amina, a Asmahn e a Shayma, nesta ordem, com protagonismo para cada uma dessas personagens, que entram na história em meio ao já narrado anteriormente. É como se as novas personagens, em cada capítulo em que são destaques, acabassem por receber o foco do holofote junto às outras. Nesses capítulos iniciais, o leitor percebe o comedimento da narradora, voluntária num centro para refugiados na Grécia. Há poucos e incisivos comentários seus, porque quem dá o tom do texto são as personagens refugiadas: a jovem que quer fugir vestida de menino, uma vez ser mais fácil sobreviver como homem; a amiga grávida que deseja encontrar o marido, já com base na Alemanha; e a mulher solitária que perdeu tudo o que tinha na vida, incluindo a própria identidade. O plano inicial, conta-nos a narradora, é transformar essas três vidas numa única família, Shayma como a mãe de Amina e de Asmahn, e avó do filho 
da segunda. Com elas, há relevantes contrapontos na construção das personagens, desde as que aceitam e reforçam o papel de submissão da mulher no mundo patriarcal, em especial muçulmano, até aquelas que lutam para desse papel se libertarem, porque temem a violência, como diz a narradora: "só um homem consegue, por artes aprendidas num lugar obscuro da masculinidade, devolver uma mulher a um passado de susto infantil, umas vezes mais parecido com um galo na testa, outras, com o terror da noite escura" (MONGINHO, 2018, p. 53).

A desconstrução identitária da personagem narradora é sutil e bastante convincente. Aos poucos, ela percebe sua figura branca, europeia e bem-nascida numa tarefa de ser uma espécie de mão salvadora daquelas meninas; percebe-se eurocêntrica, ao mesmo tempo em que convive com voluntários de outras nacionalidades, dando-se por conta de que também vem de um espaço periférico e que ninguém por ali sabe muito bem o que há em Portugal: "Também vim na esperança de que alguns de vós possam seguir para o meu país acolhedor. Mas nesta ilha não há uma única estrutura com ligação a Portugal" (MONGINHO, 2018, p. 32). A narradora questiona sua intenção messiânica e, de certo modo, relaciona-a, metonimicamente, a Portugal, país destinado à glória, mas afogado nos próprios sonhos de grandeza, de civilizar o outro. Diz ela: "Que figura fazia eu ali, pequena e atarantada, com um tablet na mão, vinda de um país que o mar só quer para servir de praia a reformados Gold" (MONGINHO, 2018, p. 73). O ano é 2016, e a conquista da Eurocopa por Portugal traz um novo suspiro de grandes feitos, depois de o país enfrentar uma gigantesca crise econômica: "A selecção portuguesa tinha acabado de ganhar o Europeu de futebol, mas a imagem de um país em respiração assistida, demasiado perto das águas cálidas, permanecia" (MONGINHO, 2018, p. 73).

J. é personagem, mas não protagonista. Utilizando-se da técnica de uma narração quase homodiegética, a narradora é testemunha das situações de precariedade, mas não só. E esse é um ponto muito interessante no livro: o cuidado em mostrar a dinâmica da convivência dentro dos campos, desenhando não apenas os contornos das personagens, aquilo que um leitor esperaria de um refugiado (o clichê dos seres tristes e desesperados), mas também avançando para o complexo mundo interior de que aquelas pessoas são feitas. Não são infelizes e revoltados jogados à esquina europeia, em busca da luz da oportunidade, mas seres compostos por sonhos, projetos e frustrações. Pessoas que riem e choram, que proferem discursos transformadores ou fúteis, que têm coragem e medo na mesma medida.

Ainda que por vezes a narradora pese a mão, preenchendo por demais a subjetividade das personagens, facilitando a vida do leitor, Julieta Monginho é uma hábil construtora de cenas, e há algumas de rara sutileza, ao mesmo tempo em que carregam uma força poderosa. São exemplos, entre tantas, a passagem da mulher que reza para que o filho não cresça: “o meu filho de doze anos e eu a rezar para que não cresçam" porque "às vezes os rapazes são levados para o sítio onde a paz não tem fim” (MONGINHO, 
2018, p. 71). Ao crescer o filho, com certeza crescerá dentro dele o ódio. Ou a cena dos óculos de mergulho negados a um miúdo pela vendedora de uma loja. Ou ainda a cena em que uma mãe, tendo recém parido um filho prematuro, com necessidade de semanas de hospitalização, tem a difícil decisão de aproveitar a imediata oportunidade para migrar à Alemanha e abandonar o filho no hospital ou esperá-lo sair dos cuidados intensivos e perder o prazo do visto.

Contudo, a tal construção de encaixe, uma personagem por vez, iluminada dentro da história da outra, descobertas por uma narradora discreta e ao mesmo tempo surpreendida (como o leitor), é interrompida por um capítulo - o quarto - intitulado "J., uma entre muitos". Nesse, a narradora revela-se também personagem num longo, repetitivo e tedioso discurso que beira a cartilha, repleto de frases feitas: "Estas vidas não são recicláveis como os botes de borracha naufragados" (MONGINHO, 2018, p. 100) ou ainda "Não são bem-vindos. Xô, saiam daqui. Este é o nosso país, esta é a nossa fronteira, este espaço é o meu” (MONGINHO, 2018, p. 109). Cerca de trinta páginas que gritam o que belamente e com sutileza já estava dito. O reforço, a redundância, a culpabilização do europeu eurocentrado desafinam, mas não chegam a comprometer a obra. Por sorte, o acidente narrativo encontra-se apenas neste quarto capítulo, pois já no quinto seguimos com novas e interessantes personagens, como Omid e Saud. O olhar da narradora para seus primeiros personagens masculinos é terno e rende outras tantas belas cenas, ao acompanhar a vida de dois jovens com opostas perspectivas: Omid, iraniano, representa o jovem engajado, antenado às redes sociais, poeta, artista que quer contar ao mundo ocidental os horrores pelos quais aquela gente passa. Saud, em contrapartida, ainda mais jovem que o primeiro, é tímido, arisco, e quer retornar a seu país, a despeito de tudo o que os outros lhe dizem: "Saud não gostava da Europa, riscava mapas, rogava pragas ao inglês” (MONGINHO, 2018, p. 139).

Omid sonhava em ser porta-voz das violências diárias que presenciava desde pequeno; Saud a prova viva de uma delas - violentado por um policial em Vial, perto do centro: "As mãos dele eram figos nojentos, por todo o corpo" (MONGINHO, 2018, p. 146). Os dois inclusive enfrentam um mesmo nível de descrença: o primeiro de que seja legítima e verdadeira toda a (fabulosa) história da vida que diz ter sido a sua; o segundo de que seja realmente uma vítima e não mais um adolescente problemático.

Também entre os últimos capítulos, Monginho amplia o espectro de suas personagens, procurando criar diferentes vozes que de alguma forma estejam envolvidas com os refugiados: voluntários, policiais, intérpretes, autoridades. Como Eleni, habitante local que presencia a chegada dos primeiros refugiados à ilha grega: "a primeira embarcação não foi avistada. Chegou. Chegaram os penitentes à praia de Megas Limnionas, àquela hora ainda vazia, sob o signo da lua. Chegaram e deram os primeiros passos. Era a Europa, o sítio onde as bombas não caíam" (MONGINHO, 2018, p. 131). Logo, ela articula-se para tentar salvá-los, indo de encontro às intenções da 
comunidade e da polícia daquele até então tranquilo e paradisíaco litoral: "Eleni decidiu que ajudaria a todos e que essa iria ser a sua vida. Mal sabia que tantos a esperavam ainda na praia" (MONGINHO, 2018, p. 133). Como também Ann, belga, professora de inglês que, juntamente com Eleni, inicia um grupo de voluntários para o auxílio dos refugiados. E como Dimitris e Juan: o primeiro, diretor temporário do campo, personagem escorregadio a lidar com chantagens da polícia local e desejos daqueles que supostamente representa; o segundo, filho de cônsul, criado no Brasil, terá uma relação próxima a Omid e tentará ajudá-lo com o documentário. Juan "encarnava o voluntário perfeito: ele ajudava, ele consolava, ele imaginava formas diferentes de torcer a realidade a favor dos desvalidos" (MONGINHO, 2018, p. 182). Já Dimitris, que diz investigar incêndios e fugas, recebe em troca o seguinte comentário de Miko, um policial: "os traficantes ficam mais uns tempos, são muito necessários aqui, dominam uma série de contactos, ajudam em fugas que nos dão muito jeito e ainda se entretêm a dar cabo uns dos outros" (MONGINHO, 2018, p. 207).

Todas essas vidas estão relacionadas desde o início da história e fazem movimentar o andamento narrativo da obra. São refugiados, como disse Bauman e repete Monginho: "batendo à porta de uma Europa apavorada pelo terror" (MONGINHO, 2018, p. 177), que chegam a um país pequeno e em crise. A resistência contra qualquer tipo de auxílio aos "invasores" é forte, porque eles são vistos como "potenciais terroristas" (MONGINHO, 2018, p. 69). Ainda assim, diz-nos a narradora: "Apesar de tudo, a Grécia faz mais do que lhe seria exigível” (MONGINHO, 2018, p. 187). Isso porque Monginho, através da sua obra, denuncia a omissão inicial dos países mais poderosos do continente: "A Europa, a tal da marca registada, vai tentando passar a bola à margem sul, retardando o processo ou parando-o, como forma de dissuasão" (MONGINHO, 2018, p. 187).

De forma geral, a narradora de Monginho sublinha o desinteresse do mundo dito civilizado, que em geral lava as mãos frente a uma das mais graves crises humanitárias do século XXI, concedendo mais atenção a animais bonitinhos em fotos nas redes sociais do que às pessoas em trânsito: "Ainda se fosse um panda fofinho, em vias de extinção, ou um gato a quem chamássemos carinhosamente Omido, ou Rod, agora um simples homem a bater à porta do mundo ocidental?" (MONGINHO, 2018, p. 178). Critica, ainda, a ajuda que vem como uma espécie de esmola dos bem-nascidos: restos aos pobres. Diz a narradora:

Quando um dia se fizer a história deste momento vergonhoso da atitude europeia e da ascensão xenófoba, do acervo fotográfico emergirão as fotografias que retratam estes móveis aleijados que um benemérito considerou à medida de quem não pertence ao mundo dos desejos, mas ao mundo das sobras, ao que restou da devastação. (MONGINHO, 2018, p. 22).

Nesse museu de objetos quebrados, utensílios que não mais cabem nas bem-aparelhadas residências europeias são a metáfora viva do desprezo e da falsa benevolência. 
Em 1824, Eugène Delacroix retratou o horror visível nas faces de mulheres e homens caídos ao chão, vencidos, alguns mortos, agredidos todos por outros homens montados em cavalos, olhar de desprezo e superioridade. A obra reproduz o massacre histórico ocorrido dois anos antes, dentro dos conflitos no movimento de libertação da Grécia do Império Turco Otomano, especificamente o ocorrido em Chios, ilha quase grudada ao território turco (BREWER, 2011). Le Massacre de Scio (O massacre de Chios) é hoje um dos pontos altos da visitação ao Museu do Louvre. Quem tiver dinheiro suficiente para viajar a Paris e pagar o ingresso do museu, pode tranquilamente apreciar a obra. Ou pode, se preferir, procurar a violência por trás da arte. Talvez seja exatamente essa diferença no olhar, apenas contemplativo ou crítico e engajado, que busca Julieta Monginho, ao desenhar outros conflitos em Chios, outros massacres, não distantes no tempo histórico, mas presentes no nosso cotidiano e tantas vezes apagados pela normalização das mortes daqueles que fingimos não saber que existem - esses seres no limbo: "As pessoas livres não fogem, deslocam-se. Os que fogem regridem à categoria de seres para o desespero, não para a vida” (MONGINHO, 2018, p. 91).

\section{REFERÊNCIAS}

ANDRADE, Carlos Drummond de. Antologia Poética. 61 ed. Rio de Janeiro: Record, 2008.

BAUMAN, Zygmunt. Estranhos à nossa porta. Trad. Carlos Alberto Medeiros. Rio de Janeiro: Zahar, 2017.

BREWER, David. The greek war of independence: the struggle for freedom and from ottoman oppression. Nova York: The Overlook Press, 2011.

MONGINHO, Julieta. Um muro no meio do caminho. Porto: Porto Editora, 2018.

Recebido para avaliação em 20/08/2020 Aprovado para publicação em 26/12/2020

\section{NOTAS}

1 Paulo Ricardo Kralik Angelini (paulo.angelini@pucrs.br) é doutor em Literaturas em Língua Portuguesa (UFRGS), professor adjunto na Escola de Humanidades da PUCRS, nos cursos de Letras e de Escrita Criativa. É professor permanente do Programa de Pós-Graduação em Letras e líder do grupo de pesquisa: “Cartografias Narrativas em Língua Portuguesa: Redes e Enredos de Subjetividade”. É autor de dezenas de trabalhos sobre literatura portuguesa hipercontemporânea.https://orcid.org/0000-0002-7096-0109 